\title{
Characterization of diabetic retinopathy in a screening program in Medellin, Colombia, in 2018
}

\section{Caracterización de la retinopatía diabética en un programa de tamización en Medellín, Colombia, en el año 2018}

\author{
José P. Vivas-Giraldo ${ }^{1,2 *}$ and Juan D. Bravo-Acosta ${ }^{1,3}$ \\ ${ }^{1}$ Ophthalmology Service, University of Antioquia, Antioquia; ${ }^{2}$ Café Ophthalmology Clinic, Manizales, Caldas; ${ }^{3}$ Retina and Vitreous Service, Hospital \\ San Vicente Fundación, Medellín, Antioquia. Colombia
}

\begin{abstract}
Purpose: To identify the prevalence of diabetic retinopathy in diabetic patients of a screening program of the Hospital San Vicente Fundación in Medellin (Colombia), to describe the sociodemographic characteristics and the type of diabetic retinopathy and to evaluate the percentage of patients with vision-threatening diabetic retinopathy. Method: This is a cross-sectional descriptive study, in which diabetic patients of all ages and both genders were evaluated in the "No more blind from diabetes" campaign of the Hospital San Vicente Fundación in Medellin, conducted in the year 2018. Results: We evaluated 610 diabetic patients from the 2018 campaign. Most of the patients had type 2 diabetes, in total 528 (74.8\%). Of the patients evaluated, retinopathy was found in 115 cases, for a prevalence of $18.8 \%$. Proliferative retinopathy was found in 17 (14.7\%) patients, and non-proliferative retinopathy was the most frequent in 98 patients $(85.2 \%)$. The subgroup of vision-threatening diabetic retinopathy was made up of $48(7.8 \%)$ patients, of which the diagnosis had not been made previously in $7(14.5 \%)$ cases. Conclusions: The prevalence of diabetic retinopathy in the population studied is comparable with some of the studies carried out in some Latin American countries. This work provides relevant local epidemiological data about diabetic retinopathy and reinforces the importance of continuing screening campaigns to prevent cases of blindness with early diagnosis and treatment.
\end{abstract}

Key words: Diabetes. Diabetic retinopathy. Prevalence. Macular oedema. Screening. Classification.

\section{Resumen}

Objetivo: El propósito de este estudio es determinar la prevalencia de la retinopatía diabética en pacientes diabéticos de un programa de tamización del Hospital San Vicente Fundación de Medellín (Colombia), describir las características sociodemográficas y el tipo de retinopatía diabética, y evaluar el porcentaje de pacientes con retinopatía que amenaza la visión. Método: Estudio descriptivo, transversal, en el que se evaluó una base de datos de pacientes diabéticos de todas las edades y ambos sexos que acudieron a la campaña «No más ciegos por diabetes» del Hospital San Vicente Fundación de Medellin, realizada en el año 2018. Resultados: Se evaluaron 610 pacientes diabéticos de la campaña de 2018. La mayoría tenían diabetes tipo 2, en total 528 (74,8\%). De los pacientes evaluados, en 115 se encontró retinopatía, para una prevalencia del 18,8\%. El tipo proliferativo se encontró en 17 (14,7\%) pacientes y el tipo no proliferativo fue el más frecuente, con 
98 pacientes (85,2\%). El subgrupo de retinopatía que amenaza la visión estaba constituido por 48 (7,8\%) pacientes, de los cuales en $7(14,5 \%)$ no se había hecho el diagnóstico previamente. Conclusión: La prevalencia de la retinopatía diabética en la población estudiada es comparable a la encontrada en algunos de los estudios realizados en otros países de América Latina. Este trabajo aporta datos epidemiológicos locales relevantes sobre esta enfermedad y refuerza la importancia de continuar realizando campañas de tamización para prevenir los casos de ceguera gracias a un diagnóstico y un tratamiento tempranos.

Palabras clave: Diabetes. Retinopatía diabética. Prevalencia. Edema macular. Tamización. Clasificación.

\section{Introduction}

Diabetes is a complex chronic metabolic disease associated with elevated blood glucose levels that require ongoing medical care and several risk reduction strategies to prevent long-term macrovascular and microvascular complications. According to the World Health Organization (WHO), its prevalence is $8.5 \%$ in people over 18 years of age, and annually between 1.6 and 2 million people in the world die as a result of it. The prevalence of diabetes is increasing globally and current figures are expected to double by $2025^{1}$.

Diabetic retinopathy (DR) is a progressive microvascular disorder that generates retinal ischemia, increased vascular permeability, retinal neovascularization, and macular edema ${ }^{2}$. It has been reported that one in three $(34.6 \%)$ diabetic patients has some type of $\mathrm{DR}^{3}$. All diabetic patients are at risk for DR and in developed countries this disease is the main cause of blindness in the working age population ${ }^{4}$. Likewise, as the prevalence of diabetes increases, the prevalence of DR also increases, including "vision-threatening DR"1.

It is very important to categorize, classify and stage the severity of DR in order to establish an adequate treatment and explain the prognosis to the patient according to the severity of the disease. The international classification of DR includes five stages: 1) no apparent retinopathy; 2) mild non-proliferative DR (NPDR); 3) moderate NPDR; 4) severe NPDR; and 5) proliferative DR (PDR) characterized by neovascularization on the disc, retina, iris or anterior chamber angle, vitreous hemorrhage or tractional retinal detachment ${ }^{2}$. Diabetic macular edema (DME) can be associated with any type of DR or occur alone?

There is a subclassification, called "vision-threatening DR", which includes severe NPDR, PDR, and DME ${ }^{5}$. It has been found that 1 in $10(10.2 \%)$ patients with $D R$ are at visual risk and the trend grows with increasing prevalence of diabetes ${ }^{3}$.

Currently, only about $60 \%$ of diabetic patients have an annual screening for $\mathrm{DR}^{1}$, which is why campaigns such as the one carried out in the Hospital San Vicente
Fundación de la Ciudad de Medellín are of vital importance to characterize the local population and detect DR cases, especially the group of patients with vision-threatening DR, so that early intervention can reduce cases of visual loss associated with the complications of this disease.

The purpose of this study was to characterize and evaluate the prevalence of DR in patients diagnosed with diabetes at the Hospital San Vicente Fundación de Medellín in the campaign «No more blind from diabetes» in 2018 , to describe the sociodemographic characteristics and the type of DR in these patients according to the international classification for the severity of $\mathrm{DR}$, and to estimate the percentage of patients in the vision-threatening DR group.

\section{Methods}

This is a cross-sectional descriptive study, in which diabetic patients of all ages and both genders were evaluated in the "No more blind from diabetes" campaign of the Hospital San Vicente Fundación in Medellín, conducted in November 2018.

In this campaign, diabetic patients from various regions of the department of Antioquia spontaneously go to the hospital once a year. Data on the history and current status of their disease are taken through a survey and a thorough ocular examination is also carried out with a dilated pupil, either with a slit lamp with a 90 diopter lens or with an indirect ophthalmoscope. All examinations are performed by ophthalmologists who record the findings, classifying patients as positive or negative for $D R$. If there is $D R$, then the patient is classified according to the international classification of DR and DME to define, according to the risk, the need of immediate treatment, deferred treatment or only monitoring.

Patients with incomplete information in the database were excluded. We did not estimate a sample size as it was a convenience sample that includes the total number of patients who meet the eligibility criteria. 
We considered the following qualitative variables: sex, the neighborhood of residence, first or subsequent attendance to the campaign, knowledge about DR, type of diabetes, active smoking, history of arterial hypertension (AHT), history of dyslipidemia, knowledge about glycated hemoglobin ( $\mathrm{HbA1c}$ ), time since the last evaluation by an ophthalmologist, complications associated with diabetes, presence of DR, type of DR, presence of DME, concurrent diagnoses and need for urgent treatment in the following week depending on the response time of the insurer, with support of the social worker. The quantitative variables evaluated were age, time of evolution of diabetes in years, and last $\mathrm{HbA1c}$ value.

This study is classified as risk-free research according to resolution 8430 of 1993 of the Ministry of Health of Colombia. Approval was requested by the ethics committee from the research department of the Hospital San Vicente Fundación. As it is a cross-sectional study from secondary sources, it is not necessary to conduct an informed consent for the use of the information collected during the "No more blind from diabetes" annual campaign. Information and patient identification are kept confidential. The information will be used only for research purposes.

The information was exported, stored, and processed in the statistical program SPSS v21 ${ }^{\circledR}$. Tables, graphics and text were prepared using the Microsoft Office Word 365 word processor.

Quantitative variables are expressed as medians and interquartile ranges (IQR) due to non-normal distribution, and qualitative variables are reported as absolute numbers and percentages.

\section{Results}

Six hundred and ten records from a database of diabetic patients from the 2018 campaign were evaluated. Demographic characteristics are summarized in table 1.

A predominance of females was observed, with 390 patients $(63.9 \%)$, and the median age of all patients was 60.5 years (IQR: $54-69)$. The majority (528, $74.8 \%)$ had type 2 diabetes. Only $43(6.1 \%)$ patients were active smokers at the time of evaluation and 381 (62.4\%) had hypertension.

For the variable "knowledge about the disease", only $202(33 \%)$ patients reported having some degree of knowledge about DR and 340 (56\%) knew what HbA1c is. In addition, $304(50 \%)$ attended the campaign again after having attended the previous year. The median
Table 1. Sociodemographic characteristics of the study population

\begin{tabular}{|c|c|c|}
\hline Variable & $n=610$ & Percentage \\
\hline Age in years, mean (IOR) & \multicolumn{2}{|c|}{$60.5(54-69)$} \\
\hline Male & 220 & 36 \\
\hline First time consultation & 276 & 45 \\
\hline Known diabetic retinopathy & 202 & 33 \\
\hline $\begin{array}{l}\text { Time from diabetes diagnosis in years, } \\
\text { mean (IQR) }\end{array}$ & \multicolumn{2}{|c|}{$12.5(5-18)$} \\
\hline Patients with type 2 diabetes & 528 & 74.8 \\
\hline Active smoking & 44 & 6.2 \\
\hline Arterial hypertension & 381 & 62.4 \\
\hline Dyslipidemia & 380 & 62.2 \\
\hline Known HbA1c & 340 & 56 \\
\hline Hba1c values, median (IOR) & \multicolumn{2}{|c|}{$7.7(6.6-8.4)$} \\
\hline $\begin{array}{l}\text { Complications associated with } \\
\text { diabetes }\end{array}$ & 139 & 22.7 \\
\hline Kidney damage & 46 & 7.5 \\
\hline \multicolumn{3}{|l|}{ Time since last evaluation } \\
\hline Less than 1 year & 312 & 52 \\
\hline More than 1 year or never & 298 & 48 \\
\hline Diabetic retinopathy & 115 & 18 \\
\hline Proliferative & 17 & 14.7 \\
\hline Non-proliferative & 98 & 85.2 \\
\hline Mild & 57 & 58.1 \\
\hline Moderate & 33 & 33.6 \\
\hline Severe & 8 & 8.1 \\
\hline Macular edema & 32 & 5.2 \\
\hline Other diagnoses & 141 & 23.1 \\
\hline Cataract & 96 & 15.7 \\
\hline Glaucoma & 17 & 2.7 \\
\hline Age-related macular degeneration & 19 & 3.1 \\
\hline Other diagnoses & 9 & 1.4 \\
\hline Requires urgent treatment & 17 & 2.7 \\
\hline
\end{tabular}

HbA1c: glycated hemoglobin; IQR: interquartile range.

$\mathrm{HbA1c}$ values was $7.7 \%$ (IQR: 6.6-8.4) in the entire sample, and in 139 (22.7\%) patients some complication associated with diabetes was detected, with associated kidney damage in 46 (7.5\%) patients. Only $312(52 \%)$ patients had a fundus evaluation by an ophthalmologist 
Table 2. Characteristics of the patients with diabetic retinopathy

\begin{tabular}{|l|c|c|c|}
\hline & PDR $n=17(14.7 \%)$ & NPDR $n=98(85.2 \%)$ & $p^{*}$ \\
\hline Time from diabetes diagnosis in years, mean (IOR) & $22.1(12-29.5)$ & $15.5(8-20.2)$ & $0.027^{\dagger}$ \\
\hline HbA1c, median (IOR) & $8.1(6.8-8.9)$ & $7.6(6.9-8.9)$ & $0.857^{\dagger}$ \\
\hline Kidney damage, $\mathrm{n}(\%)$ & $4(23.5)$ & $16(16.3)$ & $0.469^{\ddagger}$ \\
\hline Diabetic macular edema, $\mathrm{n}(\%)$ & $6(35.2)$ & $26(26.5)$ & $0.457^{\ddagger}$ \\
\hline
\end{tabular}

HbA1c: glycated hemoglobin; NPDR: non-proliferative diabetic retinopathy; PDR: proliferative diabetic retinopathy.

${ }^{*}$ Statistical significance $<0.05$

†Mann-Whitney U test

‡Chi-square.

or optometrist in the previous year. The most frequent concurrent diagnosis was cataract, in 96 (15.7\%) patients.

Of the patients evaluated we found DR in 115, representing a prevalence of $18.8 \%$ (table 2). In 44 (38.2\%) cases, the diagnosis of DR was de novo. There was a predominance in women, with $74(64.3 \%)$ diagnosed with DR. The prevalence of DR was higher in patients with type 1 diabetes (24.3\%) than in those with type 2 diabetes (17.9\%). Eighty-two (71.3\%) patients with DR also had hypertension. The type of DR according to the international classification is listed in table 1 . We found PDR in 17 (14.7\%) patients and NPDR in 98 patients $(85.2 \%)$. From this group, mild NPDR was observed in $57(58.1 \%)$ patients, moderate NPDR in $33(33.6 \%)$, and severe NPDR in $8(8.1 \%)$. The median time of evolution of diabetes in patients with and without DR was 16.2 years (IQR: 8-22.7) and 10 years (IQR: 4-16), respectively. A median $\mathrm{HbA} 1 \mathrm{c}$ of $8.2 \%$ was found (IQR: 6.98.8 ) in the group of patients with $D R$, while in patients without DR it was $7.2 \%$ (IQR: 6.6-8.2). Of the 115 patients with DR, $32(27.8 \%)$ had DME at the time of evaluation. Furthermore, 18 (15.6\%) patients with DR had some degree of kidney damage. Table 2 shows the data of the patients with PDR and NPDR.

In the 32 cases (5.2\%) with DME, the median time of evolution of diabetes was 11.5 years (IQR: 6.8-16.7). The median $\mathrm{HbA} 1 \mathrm{C}$ in patients with DME was $8.8 \%$ (IQR: 7.2-11.8).

The subgroup of vision-threatening DR (severe NPDR, PDR and DME) was made up of $48(7.8 \%)$ patients, and $7(14.5 \%)$ patients had not been previously diagnosed. In this subgroup, only $10(20.8 \%)$ patients had received some type of treatment, either with retinal laser photocoagulation or intravitreal injections of antiangiogenics. They had a median HbA1c of $8.6 \%$ (IQR: 6.8-9). In this subgroup with a high risk of vision loss, $10(20.8 \%)$ patients had some degree of kidney damage and $12(25 \%)$ required referral to their insurers to initiate urgent management. All patients in this group had been previously evaluated at some point by an ophthalmologist.

Overall, 17 (2.7\%) patients required urgent referral and we requested complementary examinations in 41 $(6.7 \%)$, that would be later evaluated by the ophthalmologists of their insurance companies.

\section{Discussion}

DR is a microangiopathic complication of diabetes, in which an increase in blood glucose leads to a shift in glucose metabolism to the sorbitol pathway and an increase in advanced glycation products and their derivatives in endothelial cells and pericytes, which ultimately leads to an alteration of the blood-retinal barrier, with leakage of blood components and formation of microaneurysms and hemorrhages ${ }^{6,7}$. These alterations generate ischemic complications that stimulate the release of growth factors such as vascular endothelial growth factor, as well as vascular proliferation, increased bleeding, and associated tractional retinal detachment ${ }^{7,8}$.

Population studies carried out in developed countries show that the prevalence of DR is $34.6 \%$, and that of PDR reaches up to $7 \%{ }^{9}$. It is said that the number of people with DR in the world will increase from 126 million in 2011 to 191 million in $2030^{10}$.

In this study, the prevalence of DR in the evaluated population of diabetic patients was $18.8 \%$, lower than that observed in population studies in developed countries $^{9}$. However, prevalence rates fluctuate between $17 \%$ and $45 \%{ }^{9}$, a range that includes the value observed in our study. When comparing with other epidemiological studies conducted in Latin America, we found varying prevalence values. In Chile, Abuauad, et al. ${ }^{11}$ reported a prevalence of $24 \%$ in a population of 
468 diabetic patients. In Mexico, Prado, et al. ${ }^{12}$ reported a much higher prevalence of $71 \%$ in a population of 13,670 diabetic patients in a span of 30 years. Other studies showed a similar prevalence, such as the one carried out by Amador, et al. ${ }^{6}$ in Honduras, that reported a prevalence of DR of $19 \%$ in a population of 177 diabetic patients. In Colombia, DR cases have increased in recent years, going from a prevalence of 12.86 per 100,000 inhabitants in 2009 to 19.76 per 100,000 inhabitants in $2014^{10}$.

Regarding the type of diabetes, despite the larger numbers of patients with type 2 diabetes in our population, we found a higher prevalence of DR in patients with type 1 diabetes (24.3\%), consistent with other studies $^{12}$. Also, we observed a higher percentage of women in patients with $\mathrm{DR}$, consistent with the reports in most prevalence studies ${ }^{6,12,13}$.

Among the factors described associated with DR include the evolution time, the values of $\mathrm{HbA1c}$, hypertension and the association with diabetic nephropathy ${ }^{14}$. In this study, it was found that the median duration of diabetes and the HbA1c value were higher in patients with a diagnosis of $\mathrm{DR}$, which is comparable to what has been described in different studies around the world8,15-17. Sixty-two percent of all diabetic patients had hypertension, and specifically $71 \%$ of patients with DR. In Cuba, Yáñez, et al. ${ }^{16}$ found hypertension in $42 \%$ of the diabetic population, which is comparable to the WHO data that report hypertension in $55 \%$ of patients with type 2 diabetes $^{14}$. Likewise, we found that $13 \%$ of patients with DR had kidney damage as a complication of the disease, compared to only $4.4 \%$ of diabetic patients without DR. These data are similar to those found in a study with 472 diabetic patients in Cuba, ${ }^{16}$ in which diabetic nephropathy was found in $3.7 \%$ of patients without DR and in $10 \%$ of patients with DR.

Since DME is the main cause of vision loss in diabetic patients ${ }^{17}$ it is important to diagnose it, taking advantage of the greater accessibility to diagnostic tests such as optical coherence tomography that facilitates early detection to initiate proper management and improve prognosis. In this study, DME was found in $5.2 \%$ of the diabetic population, which is in the expected range according to the reported global prevalence, which varies according to the region ${ }^{18}: 1.8 \%$ in countries like Chile ${ }^{19}, 3.8 \%$ in the United States of America $^{15}$ and as high as $15 \%$ in Turkey ${ }^{17}$.

A non-linear relationship has been described between $\mathrm{HbA} 1 \mathrm{c}$ values and $\mathrm{DME}^{15}$, and this is associated with a longer duration of diabetes. In the present study, we also found that in patients with DME, both the time of evolution and $\mathrm{HbA1c}$ values were greater compared to patients without DME.

The world has seen an increase in the prevalence of vision-threatening DR as diabetic patients increase, and it has even been found that in up to $11.1 \%$ of these cases there was no previous diagnosis of DR, ${ }^{5}$ due to failures or scarcity of screening programs. In the present study, $14 \%$ of the patients with vision-threatening DR had no previous diagnosis of DR, consistent with the figures described. The prevalence of vision-threatening DR was $7.8 \%$, a value comparable with the prevalence in different regions of the world, such as Sweden, where Gustafsson and Hellgren ${ }^{20}$ found a prevalence of $6.8 \%$. The incidence of vision-threatening DR, as described, is related to the time of evolution of diabetes, and according to a study carried out in Liverpool, it increases from $0.3 \%$ in the first year to $3.9 \%$ in the fifth year of screening ${ }^{21}$.

Considering that DR has the potential to be the leading cause of vision loss and blindness worldwide, and that $80 \%$ of blindness secondary to DR is preventable with early diagnosis and treatment, especially In patients with vision-threatening $D R$, it is evident the relevant effect that effective and controlled screening programs have on this dramatic public health problem, with the aim of having a better planning of the needs and costs associated with the treatment of these patients, and thus accurately estimate the magnitude of $\mathrm{DR}, \mathrm{DME}$ and vision-threatening $\mathrm{DR}$ and its risk factors in the different Latin American regions.

\section{Conclusions}

The prevalence of DR in the population studied is comparable to that observed in some of the studies carried out in Latin America. $\mathrm{HbA1c}$ values and the time of evolution of diabetes are decisive in the appearance of DME and the loss of vision. Despite the limitations of this study, as it is cross-sectional, basing much of its information on surveys and the heterogeneity of patients, we consider that it provides local epidemiological data of interest and also reinforces the importance of screening programs.

\section{Acknowledgments}

Special thanks to the entire work team of the "No more blind from diabetes" campaign that is carried out every year and that includes retina specialists, ophthalmologists, residents, medical students and all the 
collaborators of the Hospital San Vicente Fundación de Medellín.

\section{Conflicts of interest}

The authors declare no conflicts of interest.

\section{Ethical disclosures}

Protection of human and animal subjects. The authors declare that no experiments were performed on humans or animals for this study.

Confidentiality of data. The authors declare that they have followed the protocols of their work center on the publication of patient data.

Right to privacy and informed consent. The authors have obtained the written informed consent of the patients or subjects mentioned in the article. The corresponding author is in possession of this document.

\section{References}

1. Preferred Practice Pattern $\circledast$ Guidelines. Diabetic retinopathy. American Academy of Ophthalmology Retina/Vitreous Panel. 2017. Disponible en: www.aao.org/ppp

2. Wu L, Fernández-loaiza P, Sauma J, Hernandez-Bogantes E, Masis M, Fernandez-Loaiza $P$, et al. Classification of diabetic retinopathy and diabetic macular edema. World J Diabetes. 2013;4:290-4.

3. Guías clínicas para el manejo de la patología ocular del diabético. Consejo Internacional de Oftalmología. 2017. Disponible en: http://www.icoph.org/

4. Williams R, Airey M, Baxter H, Forrester J, Kennedy-Martin T. Epidemiology of diabetic retinopathy and macular oedema: a systematic review. Eye. 2004;18:963-83.
5. Huang OS, Tay WT, Ong PG, Sabanayagam C, Cheng C, Tan GS, et al. Prevalence and determinants of undiagnosed diabetic retinopathy and vision-threatening retinopathy in a multiethnic Asian cohort: the Singapore Epidemiology of Eye Diseases (SEED) study. Br J Ophthalmol Publ. 2015;99:1614-21.

6. Amador-Rosa ME, García JA, Amador-Rosa ME. Prevalencia de retinopatía diabética en el Instituto Nacional del Diabético de Honduras, en el periodo febrero-julio 2016. Arch Med. 2016;12:1-7.

7. Zhang K, Ferreyra HA, Grob S. Diabetic retinopathy: genetics and etiologic mechanisms. En: Ryan SJ, editor. Retina, 5th ed. Philadelphia: Elsevier Saunders; 2013. p. 925-39.

8. Vallejo EV, Rodríguez FJ. Epidemiología de la retinopatía diabética y su relación con la diabetes. Rev Colomb Endocrinol Diabetes Metab. 2016;3:12-5.

9. Yau JWY, Rogers SL, Kawasaki R. Global prevalence and major risk factors of diabetic retinopathy. Diabetes Care. 2012;35:556-64.

10. Análisis de situación de salud visual en Colombia. Ministerio de Salud de Colombia. 2016. Disponible en: https://www.minsalud.gov.co

11. Abuauad S, Guzmán $P$, Urzúa C. Prevalencia de retinopatía diabética y edema macular en población diabética del CESFAM Cordillera Andina de Los Andes. Rev Chil Salud Publica. 2014;18:81-6.

12. Prado-Serrano A, Guido-Jiménez DMA, Camas-Benítez DJT. Prevalencia de retinopatía diabética en población mexicana. Rev Mex Oftalmol. 2009;83:261-6.

13. Chibás AR, Lozada IR. Caracterización de retinopatía diabética en pacientes del Policlínico Universitario "Asdrúbal López". Rev Inf Cient. 2009:61:1-11.

14. World Health Organization. Prevention of blindness from diabetes mellitus: report of a WHO consultation. Geneva: WHO; 2006.

15. Varma R, Bressler NM, Doan Q V, Gleeson M, Danese M, Bower JK, et al. Prevalence of and risk factors for diabetic macular edema in the United States. JAMA Ophthalmol. 2014;132:1334-40.

16. Yáñez B, Murillo JP, Arbañil H. Diabetic retinopathy: prevalence and associated risk factors. Revista Médica Carrionica. 2016;3:3-14.

17. Acan D, Calan M, Er D, Arkan T, Kocak N, Bayraktar F, et al. The prevalence and systemic risk factors of diabetic macular edema: a cross-sectional study from Turkey. BMC Ophthalmol. 2018;18:1-8.

18. Lee R, Wong TY, Sabanayagam C. Epidemiology of diabetic retinopathy, diabetic macular edema and related vision loss. Eye Vis. 2015;2:1-25.

19. Soto $A$, Cruz $C$. Retinopatía diabética y edema macular diabético: prevalencia en una población de atención primaria de Antofagasta. Rev Chil Salud Pública. 2018;22:155-60.

20. Gustafsson S, Hellgren K-J. Sight-threatening diabetic retinopathy in a Swedish County. Orebro University; 2017. Disponible en: http://urn.kb.se/ resolve?urn=urn:nbn:se:oru:diva-66795

21. Younis N, Broadbent DM, Vora JP, Harding SP. Incidence of sight-threatening retinopathy in patients with type 2 diabetes in the Liverpool Diabetic Eye Study: a cohort study. Lancet. 2003;361:195-200. 